\title{
Rare dermoscopic image of the "sarcopte" in a new born
}

\section{Abstract}

A 40-day-old new born, from a non-consanguineous marriage, the mother reports the concept of normal pregnancy, medicalized vaginal delivery with good adaptation to ectopic life. Parents present in the emergency due to agitation, and lesions on the body level in their baby. The dermatological examination showed pustules and seropapules diffuse on the body level, scalp and palmar plantar, and a background of erythema.

\author{
Volume 3 Issue 6 - 2019
}

\author{
Rasso Asmae, Zakia Douhi, PR Hanane \\ Baybay, PR Sara Elloudi, PR Fatima Zahra \\ Mernissi \\ Department of dermatology, CHU Hassan II, Fez, Morocco
}

Correspondence: Rasso Asmae, Department of dermatology Fez, CHU Hassan II, Morocco Email rassasmae@gmail.com

Received: October 26, 2019 | Published: November 29, 2019

\section{Dermoscopy}

The dermoscopic examination of the interdigital spaces showed "sarcopte" with a triangular pigmented head called "delta sign", two pairs of hind legs pigmented, and a complete transparent sarcopte body, without scabious sillions (Figure 1). Dermoscopy allowed us to confirm in vivo the suspicion of scabies.

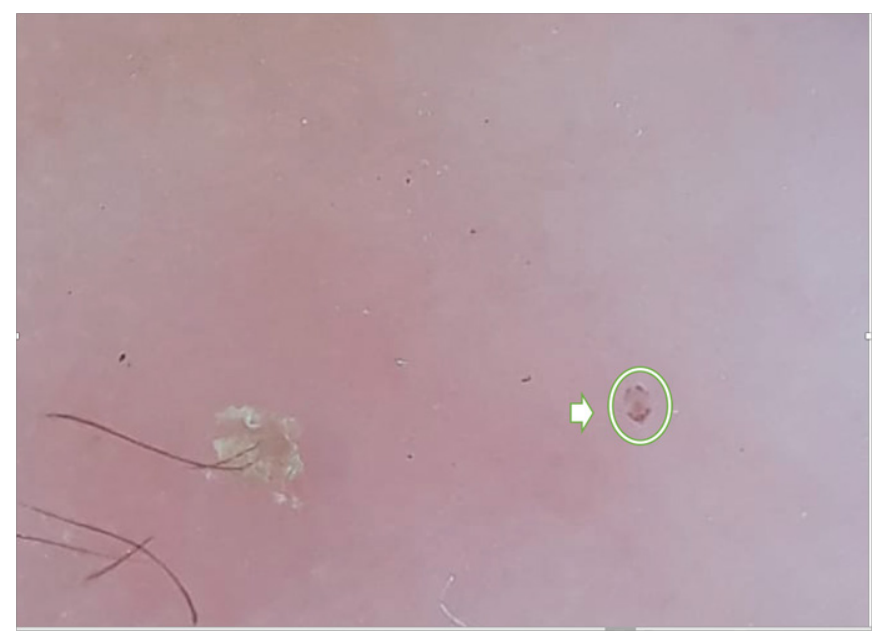

Figure I Dermoscopic examination (magnification ${ }^{\circ} \varnothing \mid 0$ ) with "sarcopte" with a triangular head "delta sign", body and hind legs, without a scabious groove.

\section{Discussion}

Scabies is a common ubiquitous ectoparasite in humans. Diagnosis can be made difficult by atypical presentations, especially in infants, with sometimes difficult diagnosis, eczematization and impetuousness of lesions. The diagnosis is traditionally based on the detection of scabious Sarcoptes under the microscope after scotch test. However, its research can be difficult, (risk of missing the sampling site) Dermoscopy is a preferred alternative, allowing a non-invasive, faster and more accurate diagnosis ${ }^{1,2}$ our case takes the particularity of visualizing the totality of sarcopte these can be due to the skin atrophy of the infant, with a very thin transparent horny layer.

\section{Conclusion}

Dermoscopy has proven its usefulness in the diagnosis of several infectious diseases, particularly scabies. It allows easy diagnosis and to guide samples in the search for the sarcopte.

\section{Conflits of interests}

Author declares that there is no conflicts of interest.

\section{Acknowledgments}

None.

\section{Funding}

None.

\section{References}

1. Cinotti E, Perrot J L, Labeille B, et al. Reflectance confocal microscopy for quantification of Sarcoptesscabieiin Norwegian scabies. $J$ EurAcad Dermatol Venereol. 2013;27(2):e176-e178.

2. Cinotti E, Perrot JL, Labeille B. Cambazard Servicescabiei Diagnosis of scabies by high-magnification dermoscopy: The "delta-wing jet" appearance of Sarcoptesscabiei. Annales de dermatologie et vénéréology. 2013;140(1):722-723. 